\title{
PROMOTING VOLUNTARY HELP-SEEKING AMONG DOCTORS WITH MENTAL DISORDERS
}

\author{
MARÍA DOLORES BRAQUEHAIS ${ }^{1,2}$, SERGI VALERO ${ }^{1,2}$, JOSEP LLUÍS MATALÍ2 ${ }^{2}$ MIQUEL JORDI BEL ${ }^{1,2}$, \\ JOSÉ EDUARDO MONTEJO², VIVIANA NASILLO ${ }^{2}$, ANTONI ARTEMAN ${ }^{1}$, JAUME PADRÓS ${ }^{1}$, \\ EUGENI BRUGUERA ${ }^{1,2}$, and MIQUEL CASAS ${ }^{1,2}$
}

${ }^{1}$ Integral Care Program for Sick Doctors, Barcelona, Spain

Galatea Clinic, Galatea Foundation, Barcelona Medical Council-Association

${ }^{2}$ Autonomous University of Barcelona, Barcelona, Spain

Department of Psychiatry and Legal Medicine, Vall d'Hebron University Hospital, CIBERSAM

\begin{abstract}
Objectives: To explore if the Barcelona Integral Care Program for Doctors with mental disorders (PAIMM, in Catalan) has achieved its goal of enhancing earlier and voluntary help-seeking amongst sick doctors. Material and Methods: We conducted a retrospective chart review of 1363 medical records of physicians admitted to the inpatient and outpatient units of the PAIMM from February 1st, 1998 until December 31st, 2011. The sample was divided into 3 time periods: 1998-2004, 2005-2007 and 2008-2011 (477, 497, and 389 cases, respectively). Results: The mean age at admission decreased ( $\mathrm{F}=77.57, \mathrm{p}<0.001)$ from the first period $(\overline{\mathrm{x}}=54.18 ; \mathrm{SD}=10.28$ years $)$ to the last period $(\overline{\mathrm{x}}=44.81 ; \mathrm{SD}=10.65$ years $)$, while voluntary referrals increased from $81.3 \%$ to $91.5 \%\left(\mathrm{Chi}^{2}=17.85, \mathrm{p}<0.001\right)$. Mental disorders other than substance use disorders grew from $71 \%$ during the 1998-2003 period, to 87.4\% (2004-2007), and 83.9\% in the last period $\left(\mathrm{Chi}^{2}=29.01, \mathrm{p}<0.001\right)$. Adjustment disorders increased their prevalence, while inpatient treatment progressively represented less of the overall clinical activity. Conclusions: Sick doctors may feel encouraged to seek help in non-punitive programs specially designed for them and where treatment becomes mandatory only when there is risk or evidence of malpractice.
\end{abstract}

Key words:

Mental disorders, Sick doctors, Physicians' Health Programs, Mental Health Services

\section{INTRODUCTION}

Physicians are reluctant to ask for help when they suffer substance use disorders (SUDs) and/or other mental illnesses [1-4]. This may be due to [5]:

- the doctors' culture of unrealistic expectations where they see themselves as super-people and showing vulnerability is identified with the risk of losing respect from peers and seniors;

- their tendency to deny the need for self-care, personal vulnerability and/or early signs of illness;
- doctors' and colleagues' difficulties in identifying emotional or mental distress and in speaking about their concerns to other people.

Some other factors may increase their inability to develop healthy coping strategies [6,7]: high self-criticism, low selfesteem, poor bonding to relatives, competitive, humiliating and status-conscious work environment, together with burn-out symptoms related to high job demands.

Easy access to self-prescription may lead to tolerance and dependence on some licit drugs, while alcohol use may

Received: December 30, 2013. Accepted: March 11, 2014.

Corresponding author: M.D. Braquehais, Psychiatric Inpatient Unit, Galatea Clinic, Integral Care Program for Sick Doctors, Galatea Foundation, Barcelona Medical Council-Association, Passeig Bonanova, 47, 08017 Barcelona, Spain (e-mail: mdbraquehais@vhebron.net). 
become a "socially accepted" strategy to deal with stressful situations [8]. Once the addiction has been established, it gets even more difficult for the sick doctor to ask for help. In fact, it is estimated that $10-14 \%$ of physicians may develop a SUD at some point in their careers [9]. Other non-addictive disorders such as depression and anxiety disorders are highly prevalent among sick doctors [10]. Delay in help-seeking not only causes greater morbidity-mortality but may also lead to malpractice behaviors [11-15]. Physician's impairment refers to those situations where physicians are rendered unable to carry forward their professional responsibilities adequately due to a variety of health issues, including a medical disease, psychiatric problems, or substance abuse [15]. The impairment may be episodic or steady, leading to psychosocial deterioration and finally, becoming dangerous both to the physician wellbeing and to their patients' safety.

The first specific programs for physicians suffering from mental disorders (Physicians' Health Programs for "sick doctors") were developed in the USA in the late 1970s, in order to identify and treat unwell doctors involved in misconduct allegations (i.e. impaired physicians) as a consequence of their mental disorders, mainly, substance use disorders (SUDs) [1,16-21]. Similar programs were developed later on in Canada [22-24], Australia [25-30], and the UK [31-33] trying to improve strategies to reach sick doctors and prevent those conditions by promoting healthy lifestyles among physicians and offering counseling if needed. Some programs are mainly devoted to providing mandatory treatment when malpractice issues are involved. This fact may prevent physicians from asking voluntarily for help when suffering from a mental disorder, as they may fear the legal implications of their demand.

In order to promote voluntary help-seeking in this professional group, a new Physicians' Health Program called the Integral Care Program for Sick Doctors (PAIMM, in Catalan, and PAIME, in Spanish) was created in Barcelona in 1998 [4,34-38]. The PAIMM has been developed in other Colegios de Médicos across Spain. In our country, all provinces have a Colegio de Médicos which acts as both a regulatory body and a medical association where all practicing physicians need to be registered.

The PAIMM can be defined as a non-persecutory, nonpunitive program that promotes voluntary outpatient and inpatient clinical treatment as well as enrollment in preventive interventions. Only when there is evidence or risk of malpractice, the treatment becomes mandatory.

The aim of this retrospective study is to see if the Barcelona Physicians' Health Program (PAIMM) has achieved the goal of promoting help-seeking among sick doctors. Our main hypothesis is that the PAIMM would have reached this objective if, after analyzing the data of physicians treated in the program from 1998 to 2011, admission progressively tended to take place in younger physicians and if there was a significant increase in voluntary referrals during this time period.

We have considered some additional hypotheses related to the main thesis of our work. It is thought that earlier and voluntary admission should be linked to:

1. An increase in the prevalence of mental disorders other than SUDs as these latter conditions are more related to malpractice issues.

2. A growth in the prevalence of non-severe mental disorders (such as adjustment disorders).

3. An increase in the prevalence of patients treated at the outpatient facilities compared with those treated at the inpatient unit.

\section{MATERIAL AND METHODS}

\section{Setting}

The Barcelona Integral Care Program for Sick Doctors was created jointly by the Department of Health of the Regional Government of Catalonia (Spain) and the Catalan Medical Association in 1998, and it is currently 


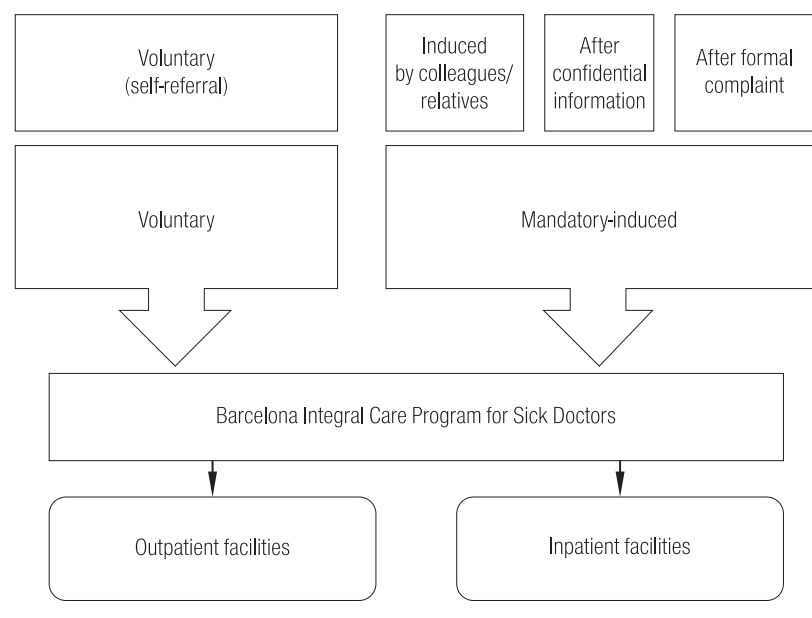

Fig. 1. Ways of access to the Barcelona Integral Care Program for Sick Doctors (PAIMM)

managed by the Colegio de Médicos of Barcelona (Barcelona Medical Council-Association).

The types of referral to the PAIMM are depicted in Figure 1 . We grouped the 4 types into 2 groups: voluntary or self-referred vs. induced-mandatory. When practice problems are involved, patient's mental health state and adequate treatment compliance are strictly controlled. If sick doctors "at risk of malpractice" do not meet all the therapeutic requirements, they receive a disciplinary action imposed by their Colegio de Médicos.

Once sick doctors are admitted to the PAIMM and have entered the program, a nickname is given to them (their last names are changed in order to warrant confidentiality). Their real identity can only be disclosed without the patient's consent if there is a threat to themselves or others. After being evaluated by a psychiatrist, each patient receives a patienttailored treatment plan depending on the severity of their disorder.

Their multi-disciplinary treatment is designed depending on the characteristics and severity of each case. Patients are included in 1 of the 2 general programs, one devoted to treating SUDs and dual pathology and another one for non-addictive mental disorders. The psychotherapeutic approach combines cognitive-behavioral techniques and motivational strategies. Patients are referred to individual and/or group therapy according to their treatment plan. All sick doctors are attended by a psychiatrist during their stay in the program. A neuropsychological assessment is performed in patients with cognitive impairments.

The PAIMM clinical services take place at the outpatient facilities (both including a Day Hospital Unit for SUDs and outpatient consultations, only for patients from Barcelona) or at the inpatient unit (devoted to treating patients from Barcelona and from the rest of the country). Sick doctors are referred to outpatient or inpatient facilities depending on the severity of their condition.

\section{Participants}

A retrospective chart review of clinical and socio-demographic data collected at admission was conducted on 1366 medical records of physicians of the Colegio de Médicos of Barcelona admitted to the PAIMM from February 1st, 1998 until December 31st, 2011.

We only chose physicians referred from the Colegio de Médicos of Barcelona because we could ensure all of them underwent an identical admission process and were offered similar preventive and treatment interventions as well as information about mental health care.

In Spain, no ethical approval is needed to conduct a chart review. However, the principles outlined in the Declaration of Helsinki were followed during this research.

\section{Clinical and socio-demographic variables}

The variables "age" and "type of referral" (voluntary vs. mandatory/induced) were obtained from medical records. The main diagnosis at admission, according to DSM-IV criteria [39] was documented by the psychiatrist who first evaluated the patient.

\section{Statistical analyses}

We created a new factor to observe the evolution of the variables age and type of referral by diving the sample into 
three time periods: 1998-2004, 2005-2007 and 2008-2011. These intervals were considered to have a balanced distribution regarding the number of cases (478, 497 and 391, respectively).

To observe the changes in the age of sick doctors at admission in these time periods, we performed an analysis of covariance (ANCOVA), including sex as a covariate factor. We also checked if the evolution of age at admission amongst sick doctors at admission was related to the evolution of physicians' age registered at the Colegio de Médicos of Barcelona during the same time period. The evolution of the type of referral and the main diagnosis were analyzed using the $\mathrm{Chi}^{2}$ test. In order to compare the diagnoses, patients were divided into 2 groups, according to the 2 main treatment programs provided by the PAIMM: those admitted for SUDs and those suffering from other mental disorders.

Additionally, we chose the most prevalent diagnoses and depicted the evolution of their distribution during the 3 time periods. Changes in the prevalence of the main diagnosis of patients treated at the inpatient unit were also described. All statistical hypotheses were 2-tailed and the alpha risk was 5\%. SPSS v20 (Chicago, IL) was used to process the data.

\section{RESULTS}

A detailed description of the sample is reported in Table 1. The mean length of the first treatment episode was 14.77 $(\mathrm{SD}=19.16)$ months. The proportion of women in the total number of admissions changed from $41.2 \%$ in the first period to $56 \%$ in the last one. This increase was statistically significant $\left(\mathrm{Chi}^{2}=23.78, \mathrm{p}<0.001\right)$. Overall, women were younger than men $(t=10.71, p<0.001)$. The mean age for women was 46.74 years $(\mathrm{SD}=10.06)$ and for men it was 52.88 years ( $\mathrm{SD}=11.13$ ). Given these findings, we decided to include gender as a covariate in order to control its potential confusion effect. Changes in
Table 1. Main characteristics of the participants in the study

\begin{tabular}{lc}
\hline \multicolumn{1}{c}{ Variable } & Participants \\
\hline Age $(\mathrm{N}=1373)(\mathrm{M} \pm \mathrm{SD})$ & $49.81 \pm 11.04$ \\
Gender $(\mathrm{men})[\%(\mathrm{n})]$ & $50.20(716)$ \\
Marital status $(\mathrm{N}=1377)[\%(\mathrm{n})]$ & \\
single & $25.80(355)$ \\
married / with a partner & $50.40(694)$ \\
divorced & $16.40(225)$ \\
widower & $1.70(23)$ \\
unknown & $5.60(77)$ \\
Medical specialty $(\mathrm{N}=1363)[\%(\mathrm{n})]$ & \\
general & $25.50(348)$ \\
family & $18.40(251)$ \\
internal/intensive & $6.30(86)$ \\
psychiatry & $5.00(68)$ \\
anesthesiology & $4.10(56)$ \\
pediatrics & $5.90(81)$ \\
digestive & $2.80(38)$ \\
other $(\mathrm{N}<20)$ & $31.90(434)$ \\
Diagnosis at admission $(\mathrm{N}=1270)[\%(\mathrm{n})]$ & \\
adjustment disorders & $29.70(377)$ \\
unipolar mood disorders & $21.20(269)$ \\
alcohol use disorders & $12.70(161)$ \\
anxiety disorders & $9.10(116)$ \\
non-alcohol substance use disorders & $4.70(60)$ \\
bipolar disorders & $4.10(52)$ \\
personality disorders & $2.60(33)$ \\
obsessive compulsive disorders & $2.40(30)$ \\
other psychiatric conditions $(\mathrm{N}<10)$ & $10.10(128)$ \\
\hline
\end{tabular}

$\mathrm{M}$ - mean; SD - standard deviation.

the mean age at admission and in the mean age of physicians registered at the Colegio de Médicos of Barcelona can be seen in Figure 2. The mean age during the 1998-2004 period was $54.18(\mathrm{SD}=10.28)$ years which decreased both during the 2005-2007 period $(\overline{\mathrm{x}}=49.33$ years, $\mathrm{SD}=10.22)$ and the last one $(\bar{x}=44.81$ years, SD $=10.65)$. Time effect was significant $(\mathrm{F}=77.57, \mathrm{p}<0.001)$. In contrast, the mean age of 


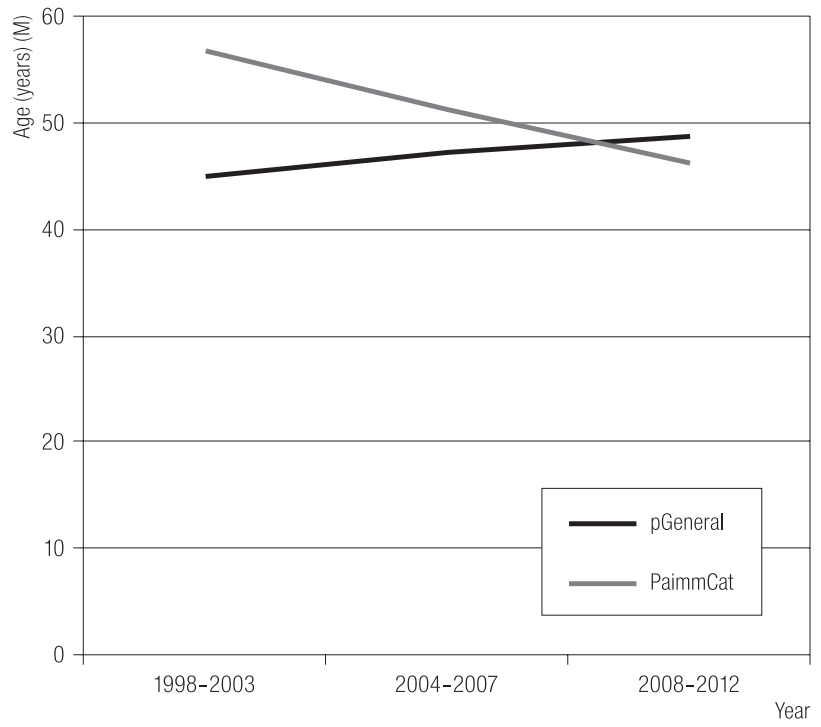

pGeneral - physicians registered at the Colegio de Médicos of Barcelona; PaimmCat - physicians admitted to the Barcelona Integral Care Program for Sick Doctors (PAIMM).

Fig. 2. The mean age of physicians at admission vs. the mean age of physicians registered in the Colegio de Médicos of Barcelona

physicians registered at the Colegio de Médicos of Barcelona during that period did not change.

Voluntary referrals increased from $81.3 \%$ in the first period to $91.5 \%$ in the last one (the mandatory/induced condition decreased from $18.7 \%$ to $8.5 \%$ ). This association was statistically significant $\left(\mathrm{Chi}^{2}=17.85, \mathrm{p}<0.001\right)$. Upon comparing the main diagnosis at admission, after 2004 there was an increase noticed in the number of patients admitted due to mental disorders other than SUDs (71\% during the 1998-2003 period, 87.4\% during 2004-2007 and 83.9\% during 2008-2011) and this change was statistically significant $\left(\mathrm{Chi}^{2}=29.01\right.$, $\mathrm{p}<0.001)$. There was also a steady increase in the prevalence of non-severe disorders such as adjustment disorders (see Figure 3). Inpatient treatment, after 2004, represented less than $20 \%$ of the clinical activity $(12.8 \%$ in the 2004-2007 period and 16.2\% during 2008-2011), while, at the beginning of the program, it stood for $30.2 \%$ of the overall clinical activity.

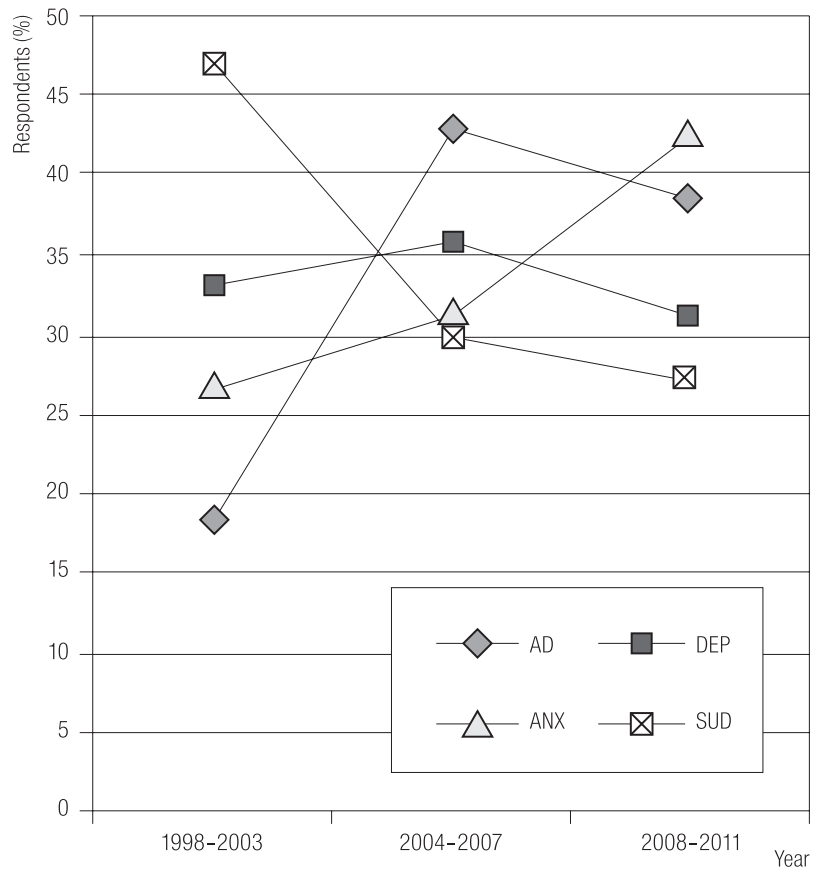

$\mathrm{AD}$ - adjustment disorder; DEP - depression; ANX - anxiety disorders; SUD - substance use disorders.

Fig. 3. Evolution of the main diagnosis at admission

\section{DISCUSSION}

This study tried to examine if the PAIMM has been successful in promoting earlier and voluntary help-seeking among physicians with mental disorders. Our findings show that the average age at admission gradually decreased during this 13-year period, while the prevalence of voluntary referrals steadily increased.

Most programs devoted to treating sick doctors in other countries report results from longitudinal studies of patients suffering from SUDs that need to be monitored in order to check their fitness to go back to practice. Given the fact that the majority of patients treated in those programs come after mandatory actions, it is difficult to compare our findings with theirs. Voluntary programs for impaired physicians, such as the Norwegian experience [40], only deal with doctors asking for counseling because of burnout symptoms and other stress-related conditions making cross-comparisons difficult as well. 
The average age of our sample is similar to that in other programs for sick doctors. McLellan et al. [41], in a followup study of physicians with SUDs, reported a mean age of 44. However, all subjects in that study were mandated to enter the program (either formally, $55 \%$, or by colleagues, family, employers or some combination of them, with the implicit threat of formal action pending the results of care). In another follow-up study of 100 cases with physicians suffering from SUDs followed by the Ontario Program [13], the mean age at enrollment was $45(\mathrm{SD}=11)$ and out of those who had started the program, 31\% had their license suspended or restricted. Dupont et al. [40] described the results of the Physicians' Health Programs developed in 48 US States and in the District of Columbia in 2005. Only 26\% of all cases were self-referrals, $31 \%$ followed a formal stipulation from their regulatory body, while the rest were induced by their state licensing boards, colleagues, treatment providers, etc. There was a mean of 34 (median: 21) new cases per year in each program.

Although it could be argued that younger age at admission (as seen in our study) might not necessarily be related to earlier help-seeking behavior (i.e. we should have the exact information about when their symptoms started), it can give an indirect clue as to the effectiveness of the program in reaching younger physicians.

We reported some additional findings in order to support our thesis. There was a steady increase in voluntary referrals and in the prevalence of patients admitted for nonaddictive mental disorders. Since most malpractice issues in doctors are related to addictions, early intervention in non-SUDs could prove to be an effective strategy to prevent addictive behaviors, as some of them appear, in doctors, as a maladaptative strategy to deal with symptoms resulting from other mental disorders. Moreover, a decrease in the prevalence of patients treated at the inpatient unit was also observed, a finding that could be related to an earlier detection of mental problems amongst doctors, which can be managed at outpatient facilities.
The observed increase in the prevalence of adjustment disorders could help support the hypothesis that doctors in Barcelona progressively feel more encouraged to ask for help in the program when they suffer from emotional distress due to external adversities. Although this behavior could have different explanations, asking for help when suffering from less severe disorders may help prevent maladaptative strategies such as self-treatment with legal drugs and/or alcohol abuse [8].

According to our data, the presence of women steadily increased over time. In other programs for sick doctors, mainly in the US, the prevalence of men is greater than women; however, this can be related to the fact that physicians who are referred for assessment or discipline or experience litigation are much more likely to be male than female [41,42]. In fact, in a recent study published by our group with physicians who followed mandatory treatment in our program [2], the majority of cases were men. Complex psychosocial factors may be related to this finding, mainly gender differences in coping strategies mechanisms.

In regard to medical specialties, General Practitioners (GPs) are overrepresented in our sample. Although this could be related to the fact that most doctors in Spain work as GPs, some studies have reported that GPs are, in fact, at higher risk to develop mental disorders compared with the rest of physicians [43-46].

The 2 main limitations of this research are related to:

1. Its design as it is a retrospective, exploratory study, conducted using medical records. However, the variables studied ("age" and "type of referral") may not be affected by information biases.

2. The lack of objective outcome variables (such as "return to work after sick leave" or a measure of improvement of the patient's general functioning).

Future research directions should incorporate structured longitudinal studies to support this revolutionary approach towards mental disorders among physicians using 
other variables such as those related to the working status and to the quality of life. Outcome variables related to the patient's improved performance at work and general areas should also be included in order to prove the effectiveness of the program.

\section{CONCLUSIONS}

New models on how to treat sick doctors in Physicians' Health Programs should not only focus on warranting a safe practice, but also on enhancing help-seeking amongst them with a non-judgmental approach to their sufferings. The PAIMM proves that this strategy can be more successful to promote voluntary referrals than merely punitive models. However, our findings need to be reinforced with data on outcome variables related to the objective benefits of the program to improve the sick doctor's integral wellbeing.

\section{ACKNOWLEDGEMENTS}

We want to thank Dr. Olaf Aasland and Dr. Karin Ro for their help in improving the quality of this work. We would also like to thank the Galatea Foundation and the Col-legi Oficial de Metges de Barcelona for their constant support and their efforts to care for the physician wellbeing.

\section{REFERENCES}

1. American Medical Association. The sick physician. Impairment by psychiatric disorders, including alcoholism and drug dependence. JAMA. 1973;223(6):684-7, http://dx.doi. org/10.1001/jama.1973.03220060058020.

2. Bloom M. Impaired physicians: Medicine bites the bullet. Med World News. 1978;19(15):40-1, 46, 50-1.

3. Herrington RE, Jacobson GR. Outlook for impaired physicians with appropriate treatment. JAMA. 1982;248(23):3144, http://dx.doi.org/10.1001/jama.1982.03330230056035.
4. Davidson SK, Schattner PL. Doctors' health-seeking behaviour: A questionnaire survey. Med J Aust. 2003; 179(6):302-5.

5. Stanton J, Randal P. Doctors accessing mental-health services: An exploratory study. BMJ Open [Internet]. $2011 \mathrm{Feb}$ [cited 2014 March 3];1(1):e000017, http://dx.doi.org/10.1136/ bmjopen-2010-000017.

6. Firth-Cozens J. Predicting stress in general practitioners: 10 year follow up postal survey. BMJ. 1997; 315(7099):34-5, http://dx.doi.org/10.1136/bmj.315.7099.34.

7. Rakatansky H. Physician suicide. N Engl J Med. 2005; 353(11):1184-5, http://dx.doi.org/10.1056/NEJMc051916.

8. Boisaubin EV, Levine RE. Identifying and assisting the impaired physician. Am J Med Sci. 2001;322(1):31-6, http:// dx.doi.org/10.1097/00000441-200107000-00006.

9. Hughes PH, Brandenburg N, Baldwin DC, Storr CL, Williams KM, Anthohy JC, et al. Prevalence of substance use among US physicians. JAMA. 1992;267(17):2333-9, http:/ dx.doi.org/10.1001/jama.1992.03480170059029.

10. Cottler LB, Ajinkya S, Merlo LJ, Nixon SJ, Bem Adballah A, Gold MS. Lifetime psychiatric and substance use disorders among impaired physicians in a physicians health program: Comparison to a general treatment population: Psychopathology of impaired physicians. J Addict Med. 2013;7(2): 108-12, http://dx.doi.org/10.1097/ADM.0b013e31827fadc9.

11. Herrington RE, Benzer DG, Jacobson GR, Hawkins MK. Treating substance-use disorders among physicians. JAMA. 1982;247(16):2253-7, http://dx.doi.org/10.1001/jama. 1982.03320410035026 .

12. Skipper GE, Campbell MD, Dupont RL. Anesthesiologists with substance use disorders: A 5-year outcome study from 16 state physician health programs. Anesth Analg. 2009;109(3):891-6, http://dx.doi.org/10.1213/ane. 0b013e3181adc39d.

13. McLellan AT, Skipper GS, Campbell M, DuPont RL. Five years outcomes in a cohort study of physicians treated for substance use disorders in the United States. BMJ. 2008; 337:a2038, http://dx.doi.org/10.1136/bmj.a2038. 
14. Redfern N. Morbidity among anaesthetists. Br J Hosp Med. 1990;43(5):377-81.

15. O'Connor PG, Spickard A Jr. Physician impairment by substance use. Med Clin North Am. 1997;81(4):1037-52, http:// dx.doi.org/10.1016/S0025-7125(05)70562-9.

16. Brown RL, Schneidman BS. Physicians' health programs what's happening in the USA? Med J Aust. 2004; 181(7):390-1.

17. Carr G. Is the Mississippi Recovering Physician Program seeing more issues related to physician stress and burnout? J Miss State Med Assoc. 2003;44(2):39-40.

18. Isaacson M. Seeing the invisible. J Ark Med Soc. 2010;106(11):252-3.

19. Talbott GD, Gallegos KV, Wilson PO, Porter TL. The Medical Association of Georgia's Impaired Physicians Program. Review of the first 1000 physicians: Analysis of specialty. JAMA. 1987;257(21):2927-30, http://dx.doi.org/10.1001/ jama.1987.03390210075028.

20. Shore JH. The Oregon experience with impaired physicians on probation. An beight-year follow-up. JAMA. 1987;257(21):2931-4, http://dx.doi.org/10.1001/jama. 1987.03390210079029.

21. Conner SL. Comparison of impaired physician programs nationwide. Md Med J. 1988;37(3):213-5.

22. Arboleda-Florez J. The mentally ill physician. The position of the Canadian Psychiatric Association. Can J Psychiatry. 1984;29(1):55-9.

23. Puddester DG. Canada responds: An explosion in doctors' health awareness, promotion and intervention. Med J Aust. 2004;181(7):386-7.

24. Brewster JM, Kaufmann IM, Hutchison S, MacWilliam C. Characteristics and outcomes of doctors in a substance dependence monitoring programme in Canada: Prospective descriptive study. BMJ. 2008;337:a2098, http://dx.doi. org/10.1136/bmj.a2098.

25. Khong E, Sim MG, Hulse G. The identification and management of the drug impaired doctor. Aust Fam Physician. 2002;31(12):1097-100.
26. Schattner P, Davidson S, Serry N. Doctors' health and wellbeing: Taking up the challenge in Australia. Med J Aust. 2004;181(7):348-9.

27. Engs RC. The drug-use patterns of helping-profession students in Brisbane, Australia. Drug Alcohol Depend. 1980;6(4):231-46, http://dx.doi.org/10.1016/0376-8716(80) 90328-2.

28. Gold N. Doctors get sick, too. Aust Fam Physician. 1980;9(5):337-42.

29. Riley GJ. Understanding the stresses and strains of being a doctor. Med J Aust. 2004;181(7):350-3.

30. Jurd SM. Helping addicted colleagues. Med J Aust. 2004;181(7):400-2.

31. Oxley J, Brandon S. Getting help for sick doctors. BMJ. 1997;314:S2-7092, http://dx.doi.org/10.1136/bmj.314. 7092.2.

32. Kmietowicz Z. New helpline set up by doctors for doctors. BMJ. 2002;325(3769):854, http://dx.doi.org/10.1136/ bmj.325.7369.854/a.

33. Oxley JR. Services for sick doctors in the UK. Med J Aust. 2004;181(7):388-9.

34. Bosch X. Catalonia makes plans to help addicted doctors. Lancet. 1998;352(9133):1045, http://dx.doi.org/10.1016/S01406736(05)60095-5.

35. Bosch X. First impaired physicians therapy program appears to be successful in Spain. JAMA. 2000;283(24):3186-7, http://dx.doi.org/10.1001/jama.283.24.3186-JMN0628-2-1.

36. Bosch X. New group to look at helping the sick doctors of Europe. Lancet. 2001;358(9294):1707, http://dx.doi. org/10.1016/S0140-6736(01)06780-0.

37. Bosch X. Spanish doctors careless of own health, says report. Lancet. 2000;355(9221):2146, http://dx.doi.org/10.1016/ S0140-6736(05)72783-5.

38. Bruguera M, Gurí J, Arteman A, Grau J, Carbonell J. [Doctors taking care of their own health. Results from a postal survey]. Med Clin (Barc). 2001;117(13): 492-4, http://dx.doi.org/10.1016/S0025-7753(01)72154-9. Spanish. 
39. American Psychiatric Association. Diagnostic and statistical manual of mental disorders. 4st ed. Text Revision (DSM-IV-TR). Washington: American Psychiatric Association; 2000.

40. Isaksson KE, Tyssen R, Hoffart A, Sexton H, Aasland OG, Gude T, et al. A three-year cohort study of the relationships between coping, job stress and burnout after a counselling intervention for help-seeking physicians. BMC Public Health. 2010;10:213， http://dx.doi.org/10.1186/1471-245810-213.

41. DuPont RL, McLellan AT, Carr G, Gendel M, Skipper GE. How are addicted physicians treated? A national survey of Physician Health Programs. J Subst Abuse Treat. 2009;37(1):1-7, http://dx.doi.org/10.1016/ j.jsat.2009.03.010.

42. Firth-Cozens J. Doctors with difficulties: Why so few women? Postgrad Med J. 2008;84(992):318-20, http://dx.doi. org/10.1136/pgmj.2008.068478.
43. Braquehais MD, Bel MJ, Montejo JE, Arteman T, Bruguera E, Casas M. [The Integral Care Program for Sick Doctors of Barcelona: mental health for a good practice]. Rev Esp Med Legal. 2012;38(3):107-12. Spanish.

44. Caplan RP. Stress, anxiety, and depression in hospital consultants, general practitioners, and senior health service managers. BMJ. 1994;309(9694):1261-3, http://dx.doi. org/10.1136/bmj.309.6964.1261.

45. Arigoni F, Bovier PA, Mermillod B, Waltz P, Sappino AP. Prevalence of burnout among Swiss cancer clinicians, paediatricians and general practitioners: Who are at most risk? Support Care Cancer. 2009;17(1):75-81, http://dx.doi. org/10.1007/s00520-008-0465-6.

46. Grassi L, Magnani K. Psychiatric morbidity and burnout in the medical profession: An Italian study of general practitioners and hospital physicians. Psychother Psychosom. 2000;69(6):329-34, http://dx.doi.org/ $10.1159 / 000012416$.

This work is available in Open Access model and licensed under a Creative Commons Attribution-NonCommercial 3.0 Poland License - http://creativecommons.org/ licenses/by-nc/3.0/pl/deed.en. 